\title{
Do Infants Need Social Cognition to Act Socially? An Alternative Look at Infant Pointing
}

\author{
Barbara D'Entremont and Elizabeth Seamans \\ University of New Brunswick
}

\begin{abstract}
Tomasello, Carpenter, and Liszkowski (2007) present a comprehensive review of the infant pointing literature. They conclude that infant pointing demonstrates communicative intent from its onset, at about 1 year of age. In this commentary, it is noted that for infants to understand communicative intent, they must have a concept of self and others as intentional agents. Evidence is reviewed to argue that this is not possible until 18-24 months of age. A leaner explanation of how infants might initially succeed in pointing tasks without understanding communicative intent is considered.
\end{abstract}

The article by Tomasello, Carpenter, and Liszkowski (2007) presents an excellent description of all the complexities involved in pointing in its mature, adult form and an eloquent review of the infant pointing literature. Ultimately, they conclude that from the very start, infant pointing demonstrates communicative intent. Their argument is situated in the context of the infants' developing understanding of others as intentional beings. The authors draw upon their previously published work arguing that at about 12 months of age, infants begin to understand both themselves and others as intentional agents (Carpenter, Nagell, \& Tomasello, 1998; Tomasello et al., 2007). This recognition of self and other as intentional agents, Tomasello et al. (2007) argue, allows infants to point in order to influence others' intentional/mental states and conversely to recognize that others point because they intend the infant to attend to some aspect of the environment. They also argue that for someone to understand a pointing gesture, the person pointing and the recipient must know or be attending to something together. This context of knowing or attending together they label common ground or joint attentional frame. Their view is a rich interpretation of infant pointing. In this commentary, our alternative look at infant pointing will consider the lean interpretation.

\footnotetext{
Preparation for this commentary was supported by Social Sciences and Humanities Research Council of Canada Grant 410-20000689. The authors wish to thank Chris Moore for helpful discussions and comments on an earlier version of this manuscript.

Correspondence concerning this article should be addressed to Barbara D'Entremont, Psychology Department, University of New Brunswick, Bag Service \#45444, Fredericton, NB, Canada E3B 6E4. Electronic mail may be sent to bdentrem@unb.ca.
}

\section{Social Cognition and the Joint Attentional Frame}

According to Tomasello et al. (2007), for a pointer and recipient to understand a pointing gesture, it is necessary that they "know some things or are attending to some things together" (Tomasello et al., 2007, p 706, emphasis in original). They call this the joint attentional frame. The joint attentional frame is necessary because pointing by itself is meaningless. All it can do is focus attention to a spatial location, and even then, only broadly. To determine what someone is pointing at and why, the pointer and receiver need some common knowledge. Using Tomasello et al.'s example, when you point at a bike leaning on a tree, for me to understand why you have pointed at this particular bike at this particular time, you and I must share some common knowledge, and I must be aware of this. For example, I must know that you know, that I want new tires. I must also infer that you want me to know about the tires on the bike being singled out. This is the crux of communicative intent. Tomasello et al. argue that infant pointing, when it emerges, contains all the components of communicative intent. The difficulty with this claim is that it rests on the assumption that self and other are similarly viewed as intentional agents.

For infants to understand communicative intent, they must have a concept of an intentional agent that includes both self and other. That is, the infant must recognize that others have intentions, that they themselves have intentions, and that the intentions of both self and other are the same. This is not straightforward because the information available about self (e.g., kinesthetic/proprioceptive information, etc.) is qualitatively different from the infor-

(C) 2007 by the Society for Research in Child Development, Inc. All rights reserved. 0009-3920/2007/7803-0002 
mation available when observing others (e.g., gross motor movements, facial expressions, etc.) (Barresi \& Moore, 1996; Moore, in press). To understand the other person's subjective experience, the infant must observe the outwardly available cues and imagine their subjective experience (Barresi \& Moore, 1996). That is, they must be able to process both perceptually present information and imagined information at the same time (Moore, in press). Moore (in press) has argued that this is not possible until the end of infancy, when infants are cognitively capable of simultaneously processing representational (or imagined) and perceptual information.

Indeed, evidence on visual perspective taking suggests that infants become aware of others' subjective experience of "seeing" at around 24 months of age (Masangkay, 1974; Moll \& Tomasello, 2006). For example, Moll and Tomasello (2006) demonstrated that 24-, but not 18-month-olds, understand that they can see things that others cannot. In their task, an experimenter and infant played together with two toys. The experimenter then left the room. While the experimenter was absent, a second experimenter arranged the toys such that, from the first experimenter's viewpoint, one was visible and one was occluded. Both were visible to the child. The first experimenter then reentered the room and began searching for the occluded object. When infants were asked to help the experimenter locate the object, 24-month-olds were more likely to hand over the occluded object whereas 18-month-olds handed over both toys equally. That is, only 24-month-olds can recognize that someone's visual perspective is different from their own (level I perspective taking).

However, it is still not clear how much 2-year-olds understand the subjective (mental) experience of seeing. It is not until the end of the 3rd year that children can reliably report where someone else is looking or when someone is looking at them based on eye direction information (Doherty \& Anderson, 1999). This is in spite of the fact that infants about $12-$ 14 months of age seem to be sensitive to the status of eyes in gaze-following studies (see D'Entremont, Yazbek, Morgan, \& MacAulay, 2006, for a review). Lastly, theory-of-mind research suggests that children become aware of others' subjective emotions and desires, even when they are different from their own, by 18 months (e.g., Repacholi \& Gopnik, 1997) and their understanding of beliefs, including the understanding that others can have beliefs that are different from their own, appears to develop around 3 years of age (Wellman \& Liu, 2004).

The point is that infants do not appear to be aware of the subjective (mental) experience of others until around 18-24 months of age and consequently do not have the requisite knowledge to have a concept of an intentional agent until this time. This does not mean that younger infants are incapable of entering into shared attentional states. The "jointness" is important. As Tomasello et al.'s (2007) review indicates, entering into shared attentional states allows infants to demonstrate some fairly impressive social acts. It does mean that when infants initially enter into shared attention, they are likely not aware of the others' individual subjective experience. We turn now to our explanation of how infants can accomplish these social acts without being aware of the subjective experience of others.

\section{The Engagement Hypothesis}

The engagement hypothesis was first proposed by $\mathrm{O}^{\prime}$ Neill (1996). She found that 2-year-olds were more likely to ask for help or use communicative gestures in obtaining a toy if their parents had not witnessed the placement of the toy. Rather than credit 2-yearolds with an understanding of others' knowledge states, she proposed that children are generally aware of when others are engaged with them and are motivated to update them of things that occurred during their absence (O'Neill, 1996). Doherty and Anderson (1999) have also used this hypothesis to explain young children's understanding of gaze. They argue that younger infants are able to do well in gaze-following paradigms through a combination of orienting and engagement. The orienting function directs infants' attention to the location that the adult is looking toward. The engagement function allows infants to determine whether adults are engaged with them and whether adults are expected to act meaningfully with the environment. Through the engagement function, infants have learned that adults are more likely to be engaged with them or the environment if their eyes are open, if they do not appear distracted, or if there is no barrier between the adult and the object of interest (Doherty \& Anderson, 1999). Thus, infants do not follow the adult's gaze if her eyes are covered or if barriers are present because they have learned from experience not to expect the adult to interact with them or to perform any interesting object-related activity under those conditions. Furthermore, Doherty and Anderson (1999) argue that young preschoolers are unable to report where someone is looking based on eye direction alone because they are unable to represent the relation between the looker and the object. In other words, they do not understand the mental/ subjective experience of the other. 
Both O'Neill (1996) and Doherty and Anderson (1999) distinguished engagement from an understanding that others have mental representations. However, neither specified what was meant by engagement other than to state that children were aware of whether their parents had attended to a particular object. Here, we suggest that engagement is akin to having a third-person understanding of others (Barresi \& Moore, 1996). That is, with engagement, infants are not able to imagine what another person's subjective experience is like from a first-person perspective. Consequently, while they may be able to use others' outward behaviors as cues to where they are directing attention or what the object of their intentional actions might be (Woodward, 1998), they are not able to reason about others' psychological states from a first-person perspective (Barresi \& Moore, 1996).

The implication of the engagement hypothesis is that infants will generally know when others are engaged with them. Initially, this knowledge will be limited to dyadic interactions. As infants become aware of others' object-directed actions (e.g., Woodward, 1998), and come to be able to deal with more than one piece of perceptually present information (around 12 months of age), they will be able to monitor others' outward cues to determine where others are attending. Now, they will be able to engage in shared attention to objects (Barresi \& Moore, 1996). We also suggest that infants of about 1 year are able to redirect others' attention, are able to keep track of when they have or have not been engaged with someone else, and generally enjoy being engaged with others (see Tomasello et al., 2007, and below for more elaboration). However, we reiterate that the monitoring of others' attention is not initially based on an understanding of the subjective, first person, perspective of others. Instead, we argue that infants rely on third-person cues to monitor attention. In the remainder of this commentary, we will demonstrate how this engagement hypothesis can be applied to the literature on pointing without assuming that the infants have an understanding of the subjective experience of others.

\section{Pointing to Influence Others}

Moore and D'Entremont (2001) provided one of the first attempts to determine whether infants were pointing to redirect another person's attention, and whether infant pointing varied according to the knowledge state of their partner. One- to 2-year-olds were presented with interesting targets while the adult was either attending to the target or attending elsewhere. They found that 12- and 16-month-olds pointed more when the adult was looking at the child. In contrast 2-year-olds pointed more when the adult either was looking at them or had attended to a different target from the child. They concluded that younger infants were pointing to enhance the interaction rather than to redirect adult attention.

Recent studies with a slightly different design and more experimental manipulations have challenged this conclusion. In two studies, Liszkowski and colleagues presented 12-month-olds with interesting events, waited until the infant pointed, and then manipulated the adult's response to the infant point (Liszkowski, Carpenter, Henning, Striano, \& Tomasello, 2004; Liszkowski, Carpenter, \& Tomasello, 2006b). In both studies, infants pointed more often if adults responded to their points with shared attention and interest compared with other conditions. The findings clearly demonstrate that 12-month-olds are not pointing simply to gain attention to self (as originally suggested by Moore \& D'Entremont, 2001). Infants did not point more frequently when the adult responded to their pointing by continuing to look at them and vocalize appropriate interest (Liszkowski et al., 2004). They also demonstrate that both sharing attention and interest are important as infants did not point more when only one of those two conditions was present (Liszkowski et al., 2004, 2006b). However, by themselves the results do not indicate that infants point to redirect another's attention. They simply show that infants are aware of where others are attending and find joint attention episodes reinforcing (i.e., they point more often under conditions where their pointing is reinforced with both attention sharing and affect). Similarly, the report of decreased repetitions of pointing during trials for this condition could mean that infants are satisfied with the adult's response for social cognitive reasons (i.e., the adult has attended where the infant intended and the infant is aware that the adult attended - as suggested by Tomasello et al., 2007). Alternatively, infants could have pointed less frequently within these trials because the adult has delivered a stimulus (the state of shared attention) that infants find reinforcing, with infants making no reference to the adult's cognitive state.

The more interesting results were obtained when adults provided a mismatch between their attentional focus and that of the infant (Liszkowski et al., 2006a; Liszkowski, Carpenter, \& Tomasello, 2006b). This condition not only generated more repeated pointing within trials than conditions where the adult shared attention and interest to the object but also more pointing than conditions where the adult 
looked at the correct object but did not share interest, or where the adult simply ignored the infant (Liszkowski et al., 2006a, 2006b). If infants were simply repeating the pointing response until they received reinforcement, all nonshared attention and interest conditions (not just mismatch) should have generated increased repeated pointing. Also, infants showed increased pointing after the interesting event disappeared when the adult had not previously attended the event compared with when she had previously attended the event (Liszkowski et al., 2006a). These findings suggest that infants not only monitor adult's attention, they also point to redirect their attention. However, this interpretation does not mean that infants attempt to influence adults' knowledge state or that they recognize that others can be knowledgeable or ignorant. According to the engagement hypothesis outlined above, infants are able to read observable cues to determine where others are attending. As infants enjoy and desire to enter into shared attentional states they may have pointed to ensure that adults were engaged with them rather than influence their mental state.

It is also not necessary to assume that infants point to inform others. Liszkowski, Carpenter, Striano, and Tomasello (2006) presented 12- and 18-month-olds with an adult displaying object-directed actions on objects. The adult subsequently lost track of the object and then began searching for it. Infants pointed more frequently to the object that the adult had acted upon immediately before searching than to a distractor object. Tomasello et al. (2007) interpret this as a motivation to provide information to others. Put differently, infants can recognize when others are knowledgeable or not, and can determine what information is required to make them knowledgeable. We suggest that the results of Liszkowski, Carpenter, and Tomasello (2006c) can be explained by considering what infants understand about object-directed behavior. Habituation studies reveal that by 9 months, infants understand that there is some connection between a person who performs an objectdirected action and the object itself. For example, Woodward (1998) demonstrated that when 9-montholds see a person reach repeatedly for one object over another, they show surprise when that person subsequently reaches for a different object. Clearly, infants understand some "connection" between the person and the object. However, that connection need not involve an understanding of the adult's subjective experience. Following the engagement hypothesis, the connection would be something like "you are the one who does $(\mathrm{X})$ on $(\mathrm{Y})$." Rather than a desire to inform, the pointing in Liszkowski, Carpenter, and
Striano et al. (2006) could be a "comment" on the object. The infant could be pointing as if to say "that's the one you were manipulating before." Again, this can be accomplished by an understanding of the third-person perspective, without any recognition of what the person does or does not know.

\section{Understanding of Others' Pointing}

Tomasello et al. suggest that 12-month-olds understand that adults point with the intention of directing their attention. Three lines of evidence are relevant here. First, they note that infants will follow the gaze or point of an adult to find a hidden toy, but only when the gesture appears to be "for" them. That is, 14- to 24-month-olds did not follow the adult's gaze when she appeared distracted, or her point if the point was produced while she was inspecting her watch (Behne, Carpenter, \& Tomasello, 2005). Second, they note that when an adult gestured nonspecifically to request a toy, 12- to 18-month-olds overlooked two toys that the infant and adult had previously played with together and handed over a third toy that was new to the adult (Tomasello \& Haberl, 2003). Lastly, they note that when an adult pointed to a toy during a cleanup game, 18-montholds responded by integrating that toy into the cleanup. In contrast when the adult pointed to the same toy during a stacking game, infants responded by integrating the toy into the stacking game. Moreover, they only did this if the experimenter had been actively taking part in the actions, and not if a new adult entered the room and pointed (Tomasello et al., 2007).

These three studies demonstrate that "jointness" is an important aspect in how infants respond to others' points. However, in each case, the infant and experimenter had either both been engaged with an action or toy or both not been engaged. Consequently, these studies do not allow us to determine whether infants were aware of the adult's subjective experience, independent of their own experience. A recent study reported by Moore (in press) used a procedure similar to Tomasello and Haberl (2003) but arranged it such that there was one toy that the experimenter and child had shared interactions with, one toy that was new to the child, but old to the experimenter, and one that was the reverse (MacPherson \& Moore, 2004, as cited in Moore, in press). All three toys were then placed on a tray and the experimenter requested a toy using the same type of request as Tomasello and Haberl (2003). The 18month-olds were more likely to hand over the toy that was new to the experimenter. However, impor- 
tantly, the 12-month-olds were more likely to hand over the toy that was new to the child. That is, the 12month-olds were responding to their own subjective experience, not the subjective experience of the experimenter (MacPherson \& Moore, 2004, as cited in Moore, in press).

\section{Conclusion}

"Jointness" appears to be essential for understanding infant pointing. Infants rarely point when they are alone. They point more when their pointing is reinforced with shared attention and interest than if it is reinforced with only shared attention (but not interest) or only interest (but an incorrect attentional focus). The pointing gesture of others is not interpreted as "for" them unless the experimenter is engaged, and this is true across a number of contexts. That is, infants only follow gestures to locate hidden objects when experimenters are engaged with them, infants only incorporate objects into goal-directed actions when the gestures are delivered by an experimenter who was engaged with them, and finally, infants will selectively hand over the toy that the experimenter and infant were not previously jointly engaged with (Tomasello et al., 2007). In this sense, pointing is deeply social.

Tomasello et al. (2007) offered a rich interpretation of these findings. They argued that from the time infant pointing emerges, infants understand the communicative intent behind this gesture. This understanding of communicative intent is based on an understanding that others, like self, are intentional agents, which, in turn, requires an understanding of the subjective experience of others. In this commentary, we offered a leaner interpretation. We reviewed evidence suggesting that infants are not aware of the subjective experiences of others until at least 18 months of age, and suggested that infants cannot understand communicative intent until this time. Consequently, we argued that it is unlikely that 12-month-olds understand that others point with the intent to manipulate others' intentional/mental states or that their own pointing influences the intentional/mental states of others. Instead, we argued that an understanding of engagement guides infants' understanding of pointing at 12 months of age. That is, 12-month-olds are able to use observable thirdperson cues to determine when adults are engaged with them, or objects in their environment. Their ability to attend to two perceptually present pieces of information also allows them to enter into shared attentional states. With this ability to monitor others' engagement, it is possible for infants to point to manipulate where adults are engaged. It also makes them excellent consumers of others' pointing by allowing them to follow a point gesture to a location or object-directed activity.

Our main argument is not that different from that of Moore and D'Entremont (2001). Specifically, the results reviewed do not support the conclusion that 12-month-olds understand the independent subjective experience of others. However, the studies reported by Tomasello et al. (2007) do alter our corollary conclusion. It is now clear that 12-month-olds are seeking an object-related response from others, that sharing attention/engagement is a goal of 12-montholds, and that they are not simply seeking attention to themselves. Further research must be conducted to demonstrate that infants can act based on understanding of the subjective experiences of others when that experience is different from their own. This would be similar to research that has shown that preschoolers understand that others can have beliefs and desires that differ from their own and these mental states can motivate behavior. Such a demonstration would add significant weight to the rich interpretation. Given the current evidence, we prefer the lean interpretation.

\section{References}

Barresi, J., \& Moore, C. (1996). Intentional relations and social understanding. Behavioral and Brain Sciences, 19, 107-154.

Behne, T., Carpenter, M., \& Tomasello, M. (2005). One-yearolds comprehend the communicative intentions behind gestures in a hiding game. Developmental Science, 8, 492499.

Carpenter, M., Nagell, K., \& Tomasello, M. (1998). Social cognition, joint attention, and communicative competence from 9 to 15 months of age. Monographs of the Society for Research in Child Development, 63, 176.

D'Entremont, B., Yazbek, A., Morgan, A., \& MacAulay, S. (2006). Early gaze following and the understanding of others. In R. Flom, K. Lee, \& D. Muir (Eds.), The ontogeny of gaze processing in infants and children (pp. 77-93). Baltimore: Lawrence Erlbaum Associates.

Doherty, M. J., \& Anderson, J. R. (1999). A new look at gaze: Preschool children's understanding of eye-direction. Cognitive Development, 14, 549-571.

Liszkowski, U., Carpenter, M., Henning, A., Striano, T., \& Tomasello, M. (2004). Twelve-month-olds point to share attention and interest. Developmental Science, 7, 297-307.

Liszkowski, U., Carpenter, M., \& Tomasello, M. (2006a). Pointing out new news, old news, and absent referents. Developmental Science, F1-F7.

Liszkowski, U., Carpenter, M., \& Tomasello, M. (2006b). Reference and attitude in infant pointing. Journal of Child Language, 33, 1-20. 
Liszkowski, U., Carpenter, M., Striano, T., \& Tomasello, M. (2006c). 12- and 18-month-olds point to provide information to others. Journal of Cognition and Development, 7 , $173-187$.

Masangkay, Z. S. (1974). The early development of inferences about the visual percepts of others. Child Development, 45, 357-366.

Moll, H., \& Tomasello, M. (2006). Level I perspective-taking at 24 months of age. British Journal of Developmental Psychology, 24, 603-613.

Moore, C. (in press). Understanding self and others in the second year. In C. A. Brownell \& C. B. Kopp (Eds.), Transition in early socioemotional development: The toddler years. New York: Guilford Press.

Moore, C., \& D'Entremont, B. (2001). Developmental changes in pointing as a function of parent's attentional focus. Journal of Cognition and Development, 2, 109-129.
O'Neill, D. K. (1996). Two-year-old children's sensitivity to a parent's knowledge state when making requests. Child Development, 67, 659-677.

Repacholi, B. M., \& Gopnik, A. (1997). Early reasoning about desires: Evidence from 14- and 18-month-olds. Developmental Psychology, 33, 12-21.

Tomasello, M., Carpenter, M., \& Liszkowski, U. (2007). A new look at infant pointing. Child Development, 78, 705722.

Tomasello, M., \& Haberl, K. (2003). Understanding attention: 12- and 18-month-olds know what's new for others. Developmental Psychology, 39, 906-912.

Wellman, H. M., \& Liu, D. (2004). Scaling theory of mind tasks. Child Development, 75, 523-541.

Woodward, A. L. (1998). Infants selectively encode the goal object of an actor's reach. Cognition, 69, 1-34. 